\title{
LA "FELICIDAD” COMO ANHELO DEL HOMBRE
}

\author{
Saby Evelyn Lazarte Oyague \\ Universidad Ricardo Palma \\ selo8012@hotmail.com
}

Consideramos suficiente lo que por si solo hace deseable la vida y no necesita nada, y creemos que tal es la felicidad. ... Es manifiesto, pues, que la felicidad es algo perfecto y suficiente, ya que es el fin de los actos. (Aristóteles, É.N.1097b 15, 20)

\section{RESUMEN}

La sociedad del siglo XXI vive cambios tan acelerados que ya pasan desapercibidos los sentimientos de amistad, sinceridad y confianza. Vivimos en medio de permanente crisis moral, social, política y económica, entre otros. Todo esto exige una mediación y adaptación a los nuevos rumbos que toma la sociedad actual. Sin embargo, si observamos desde el aspecto de la subjetividad humana, es importante saber cuáles son las emociones que provocan esta situación. Por la vida tan acelerada que nos impele competir nos toca saltar vallas para alcanzar el éxito. Pero ¿qué es el éxito? En estricto, si se relaciona con la felicidad, las personas no buscan éxito, buscan "estar bien”, "estar satisfechos", "estar contentos". Así se conocerá la felicidad.

\section{PALABRAS CLAVE}

Felicidad/ Éxito/Vida/Siglo XXI/Humanidad

\begin{abstract}
the society of the twenty-first century is experiencing such accelerated changes that the feelings of friendship, sincerity and trust go unnoticed. we live in a permanent social, political and economic crisis. all this requires a mediation and adaptation to the new directions that the current society takes. however, if we look from the aspect of human subjectivity, it is important to know what the emotions that provoke this situation by the life so accelerated that we are compelled to compete and jump fences to achieve success. but what is success ?. in strict terms, if it is related to happiness, people do not seek success, they seek to "be well", "to be satisfied", "to be happy".
\end{abstract}

\section{KEYWORDS}

Happiness / Success / Life / 21St Century / Humanity 


\section{INTRODUCCIÓN}

Si 1 felicidad es el anhelo del hombre ¿que se busca en la vida?, será quizas una representación material de la felicidad o quizás un estado emocional del ser feliz. De momento parece un tanto vacía pero de inmediato rivaliza muchas otras preguntas como ¿qué es ser feliz?, o en qué radica la felicidad. Sin embargo, es tan importante lo que sentimos en cada momento de la vida que se convierte en una fuente del fortalecimiento del ser para la felicidad, estamos tan acostumbrados a despreciar, maltratar, lastimar y muchos otros verbos o adjetivos característicos de las actitudes negativas del comportamiento humano. Qué sucede en nuestra sociedad que hacemos de la interacción negativa, nuestro modo de vida, un modo de vida que nos denigra como seres humanos, en la mayoría de casos humilla protagonizando el odio y el rencor como medio de interacción social.

\section{LA RACIONALIDAD HUMANA Y LA CARACTERÍSTICA BIOLÓGICA}

La vida es un anhelo de la humanidad, decimos anhelo, ya que es el deseo máximo de la realización del ser puesto en acto. El hombre como ser vivo, se descubre por la biología como Homo sapiens. Esta definición indica la "especie", la especie es la unidad básica de la clasificación biológica; etimológicamente se interpreta del latín Homo (hombre), sapiens (inteligente, razonable, prudente, sabio). Esto significa que es el único ser en el planeta con una naturaleza particular que lo diferencia y lo distingue de otro ser vivo, si bien las plantas y los animales son seres que existen en la naturaleza, el hombre posee una naturaleza particular, pues tiene la capacidad de razonar, conocer, dado que posee un cerebro complejo, que le permite la realización del ser para ser humano. Es posible así un ser humano dispuesto y predispuesto biológicamente a la comprensión (conocimiento y reflexión) de su entorno, de su naturaleza, y junto con esto a la realización de actividades, pues descubre que sus manos le prometen trabajo, el hombre se descubre con otros igual a él y vive en comunidad desarrollando una cultura de vida, se desarrolla bajo la plenitud de su comprensión, y asume la vida, enfrenta retos, construye y destruye, la vida de los seres humanos se traduce en una secuencia de vivencias que se dirigen en una constante búsqueda de felicidad.

Desde la antigüedad el filósofo estagirita Aristóteles sitúa al hombre como un "Animal racional", dice: "Los otros animales viven primordialmente por acción de la naturaleza [....] el hombre, en cambio, vive también por acción de la razón, ya que es el único entre los animales que posee razón" (Política, libro VII, 12, 1332 b). 
Además, el hombre es bueno por naturaleza y desde la antigüedad griega se concibe a un hombre bueno y virtuoso que busca ser feliz, así en el pensamiento griego se consideró que la "felicidad es una actividad del alma de acuerdo con la virtud perfecta" (É.N.1102a 5). En efecto, la felicidad es el anhelo del ser humano, quien al encaminarse hacia el bienestar se encamina hacia la satisfacción de su ser y concibe ser feliz.

Feliz será la vida deseada y anhelada, pero bastó que el hombre se aferre a ser feliz a causa del azar, para generar una suerte de confusión en los caminos hacia esa felicidad. Cuestión que nos permite plantear la interrogante ¿la felicidad existe independientemente del hombre o es él quien hace existente la felicidad?. En el primer caso, la felicidad tendría que tener existencia material, esto es que cumpla con las cualidades o características de ser denominado felicidad, sin embargo, tal cosa no existe,-excepto que alguien demuestre a esa "cosa"-a pesar de ello, algunos seres humanos atribuyen felicidad a la obtención o disfrute de algunos bienes materiales, y en este caso no es la felicidad existente, sino que se valora el bien y, a consecuencia de ello, se denomina al estado emocional de disfrute del bien "felicidad". De este modo, podemos darnos cuenta que nuestra cuestión puede ser dirigida por el segundo caso, vale decir, es el hombre quien hace que exista la felicidad, de tal modo que si podemos atribuir a la felicidad un tipo de existencia deberá ser de existencia ideal. Como es sabido, una de las características de todo objeto ideal es la ausencia de existencia material, y la posibilidad de existir solamente en la mente de quien la piensa, o de quienes comparten ese pensamiento.

\section{EL ESTADO "POSITIVO DEL SER HUMANO"}

Pero no hay duda que en algún momento nos hemos preguntado ¿qué es ser feliz?, o tal vez vivimos bajo el deseo iquiero ser feliz!, o incluso con el anhelo de encontrar la felicidad. Sin embargo, debemos darnos cuenta que la felicidad está en nosotros, ya lo intuían los filósofos en la Antigüedad: "la felicidad es una actividad del alma", y dado que el ser humano es dotado de cuerpo y alma, es quien puede percibir la sensación de felicidad, o mejor, dado que la felicidad es una cualidad del alma, por ello podemos ser felices cada instante, en tanto que mi alma se sacie de ella.

El estado de saciedad se convierte en un apetito de alma que se manifiesta en el ser humano como satisfacción, tranquilidad, alegría, pasividad, nobleza, en tanto que nos permita bienestar considerando que son factores emocionales favorables para el ser humano. De otro modo, son estados positivos del hombre, lo cual nos permite estar bien 
con uno mismo y con el entorno (los demás, el otro, el ambiente); porque puede ocurrir que alguien se sacie con el dolor y lo disfrute e incluso atestigüe que se siente bien, pero este estado de saciedad se convierte en una forma de corrupción del alma, dado que se considerará bienestar si se cumple el factor humano del "bien" y lo bueno.

A lo largo de la historia de la humanidad, los seres humanos, se pasan la vida buscando la felicidad, realizando determinados actos que muchas veces nos llevan a conseguirla, en otras ocasiones realizamos actos que no no ofrecen la oportunidad de abrazarla. En ambas circunstancias cuando estos actos son analizados y estudiados por la ciencia, llegándose a explorar categorías que nos permitan comprender la complejidad del ser humano: la personalidad y el comportamiento. Los estudiosos, nos brindan recomendaciones que van desde cómo ser feliz, hasta cómo evitar ser infeliz, sin embargo, la psicología nos asiste con investigaciones que nos permiten entender determinados factores y problemas que surgen tanto con el comportamiento como en la personalidad.

\section{LA PSICOLOGÍA DE LA FELICIDAD EN EL PERÚ}

Desde finales del siglo XIX, la psicología se ha dedicado a explorar áreas especializadas para la comprensión del ser humano. Así se propicia la aparición de la psicología experimental y el psicoanálisis. La psicología del siglo XX se desarrolla en diversas vertientes como el conductismo de Watson; la terapia racional emotiva conductual de Albert Ellis; la terapia cognitiva de Beck; la psicología cognitiva; la terapia Gestalt; entre otros. Estos estudios correspondían necesariamente al entorno sociocultural desde donde se comprende la complejidad humana.

Sin embargo, en el siglo XXI los múltiples cambios en la sociedad arremeten una transformación acelerada del entorno sociocultural, los ideales, los anhelos en la vida y el sentido de la existencia humana cobran nuevas vertientes y la complejidad del hombre crece. Así, hoy se hace evidente la aparición de una nueva comunidad de investigaciones en psicología, que ya no solo buscan estudiar los problemas de conducta o personalidad, que agobian al ser humano por distintos factores, sino más bien ahora la psicología busca abordar el fortalecimiento de la conducta desde lo favorable y positivo. Hoy nos presentan la "psicología positiva", como una nueva forma de estudio que se preocupa por promover el mejoramiento de la calidad de vida, y prevenir trastornos conductuales. Su principal difusor es Martin Seligman de la Universidad de Pennsylvania, profesor que propicia la psicología positiva desde hace algunos años. Su enfoque se caracteriza por estudiar los estados positivos del ser humano, en el fortalecimiento humano y en el disfrute de la vida a plenitud. 
En el Perú, Reynaldo Alarcón señala que:

la originalidad de la psicología positiva reposa en su orientación hacia el estudio de áreas inexploradas del psiquismo y conducta humana, conectadas al bienestar psicológico, la realización del individuo como persona y el desarrollo de virtudes cívicas para vivir en armonía en una sociedad plural. (2009; 22-23).

La psicología positiva se inserta en la reflexión y la investigación psicológica peruana, siendo así que conlleva a una nueva exploración del comportamiento y la personalidad. El maestro Reynaldo Alarcón enfoca la nueva propuesta con una visión que plasma en sus investigaciones. En psicología se incrementa el repertorio bibliográfico peruano, desde la década de los años 60 en adelante, con los aportes de Reynaldo Alarcón pues para el desarrollo de la psicología en el Perú los aportes son notorios e invalorables, sus investigaciones son difundidas en revistas especializadas del país y del exterior.

Entre sus publicaciones figura Historia de la Psicología del Perú (2000), trabajo de investigación donde se da cuenta de la visión orgánica que corresponde a una articulación de la historia de la psicología en el Perú. Vincular el pasado y el presente para fundamentar su desarrollo, pues aquí se tematizan las ideas filosóficopsicológicas en el Perú colonial y en el Perú republicano. Presenta a los pioneros del Perú contemporáneo en la década del 30 entre ellos Honorio Delgado y Walter Blumenfeld, así se va descubriendo cómo se desarrolla la psicología en el Perú, sobre todo cómo se fundan los departamentos psicológicos y la fundación de la Sociedad Peruana de Psicología. Seguidamente fundamenta la profesionalización de la psicología y las orientaciones teóricas de la psicología en el Perú entre 1960 y 1999. Junto a este libro podemos encontrar otro de igual valor que articula una visión amplia y global. En este sentido dirige su esfuerzo a un análisis de la psicología en América latina, cuestión que desarrolla en Estudios sobre psicología Latinoamericana (2002).

Seguidamente, presentó Psicología de la felicidad. Introducción a la psicología positiva (2009), libro que constituye su obra capital, por cuanto estructura el método de investigación de la psicología positiva y propone la idea básica sobre el hombre, su conducta y comportamiento; busca renovar el estudio del hombre a partir del fortalecimiento de las virtudes y los sentimientos positivos, pues la psicología del siglo XX se preocupó fundamentalmente de los sentimientos negativos, siendo estudiados como trastornos o anomalías de la personalidad, como un seto a ello, la propuesta asumida por Reynaldo Alarcón fortalece el camino de 
la felicidad como bienestar. Es primordial el estudio del comportamiento humano, para lo cual se considera que:

Los comportamientos positivos son opuestos a estados psicológicos negativos, como neurosis, ansiedad, cólera, depresión, trauma, psicosis, esquizofrenia, y otros tantos que denotan desordenes del comportamiento (Alarcón, 2009; 53).

A lo largo de muchos años la psicología se enfocó en trastornos y debilidades que provocaban el estado de dolor, angustia, sufrimiento, los cuales caracterizaban comportamientos negativos en la conducta del hombre. Ahora se busca renovar de modo inverso este acercamiento al estudio del comportamiento por lo cual -dice Alarcón- "el término positivo, que adjetiva a psicología, expresa experiencias agradables, placenteras, de satisfacción y bienestar personal, por ejemplo, felicidad, optimismo, amistad, amor, gratitud, buen humor" (Alarcón, 2009; 53).

Si el camino para la felicidad se comprende desde un estado de la conciencia, si se busca fortalecer la conducta del hombre con estímulos que lleven a una manifestación de la voluntad, y además se induce a la interacción humana al predominio de la cooperación, la socialización de las nuevas generaciones se fortalecerán dando importancia al bienestar social y colectivo antes que al bienestar individual y privado. Entonces solo así lograremos un porvenir conducido por pautas hacia la satisfacción del bien; pues, "La psicología positiva tiene por finalidad potenciar las propiedades más genuinas y positivas del comportamiento humano" (Alarcón, 2009; 55).

De esta manera es posible considerar la propuesta de la psicología positiva, es la alternativa que renueva la investigación psicológica y se tematiza un nuevo frente de estudio donde lo central se enfoca desde el comportamiento humano. Señala Alarcón sobre la psicología:

Su objetivo como ciencia es ampliar las fronteras del conocimiento acerca del psiquismo y el comportamiento humano; en tanto que como profesión, la psicología tiene como meta brindar consejo psicológico y restaurar el comportamiento alterado. A estos propósitos habría que sumar, optimizar el funcionamiento psicológico del individuo, a fin de que pueda alcanzar su realización personal (Alarcón, 2011; 243).

El profesor Ramón León, comenta sobre el impacto de la tendencia liderada por Reynaldo Alarcón, al sostener que: 
Si en los años 1970 Alarcón difundió y promovió la psicología transcultural, en lo que va de esta centuria lo encontramos dando a conocer y estimulando el importante movimiento de la psicología positiva. $\mathrm{Su}$ muy reciente libro Psicología de la felicidad es el aporte peruano a este movimiento, cuya importancia va in crescendo $(2014 ; 150)$.

También Nelly Ugarriza señala sobre Reynaldo Alarcón que sus ideas reflejan la sabiduría de una persona sensible, identificada con su realidad y comprometida con las transformaciones que deben ocurrir en nuestra sociedad con miras al desarrollo de una psicología positiva cuyo ejercicio, como él mismo expresa, favorezca el desarrollo el bienestar psicológico del ser humano (2014: 163). Además agrega, no cabe duda que en el siglo XXI la psicología positiva será la ciencia psicológica del hombre integral, de sus procesos internos y de la expresión objetivada de ellos a través del comportamiento (Ugarriza, 2014: 162).

\section{LA FELICIDAD EN EL PERÚ ES LA MANIFESTACIÓN DE LOS PERUANOS}

Retomo aquí una pregunta planteada en la introducción ¿Qué se busca en la vida?. De repente el optimismo nos hace caer en la desesperación que provoca la insatisfacción, y así empezamos a enrollar la madeja con distintos estados de insatisfacción en los que el hombre se encuentra a diario. Por supuesto, nadie estará satisfecho hasta que sacie aquello que busca, que desea, que quiere, que anhela. $\mathrm{Y}$ es aquí donde encontramos nuevamente el problema. Volvamos al análisis sociocultural y visualicemos el comportamiento de la sociedad y la colectividad humana, pues, sin duda encontraremos un reflejo de la conducta individual en lo grupal. Si un niño vive bajo constante maltrato, siendo la víctima, en cuanto tenga la oportunidad de cambiar el rol, él será el victimario y esto influye como referente negativo en su entorno, lo cual provocará una reducción de posibilidades de desarrollo social y, por ende, un acrecentamiento de insatisfacción personal.

Desde 1990, el Programa de las Naciones Unidas para el Desarrollo (PNUD), creado en 1965 por la Organización de las Naciones Unidas (ONU); inserta el concepto de "Desarrollo Humano" como hito que dirigirá el "bienestar de la gente", busca las mejoras en la calidad de vida, enfocado en el bienestar del ciudadano. Con este propósito, el PNUD inició la publicación del Informe sobre desarrollo humano, el cual se encuentra en su vigésima cuarta edición, donde cada año expresa el análisis global, las cifras y los logros para la elaboración de iniciativas que ofrezcan planes, proyectos y políticas que consideren a la "gente" como el centro de atención para las estrategias de desarrollo. 
El concepto que aquí llama nuestra atención es "desarrollo". Comúnmente el desarrollo es el reflejo de "una mejor situación respecto de la anterior". Si lo estudiamos desde el campo de las ciencias, encontraremos distintas categorías: desarrollo social, comprometido con la superación de los niveles de pobreza; desarrollo económico, que se relaciona con la acumulación de riquezas para satisfacer necesidades; desarrollo sostenible que tiene que ver con el uso de los recursos naturales involucrando la perdurabilidad en el tiempo. Desde la filosofía se analizó la relación entre desarrollo y subdesarrollo, el cual tiene que ver con la relación de dependencia y dominación en la que se encuentran los pueblos de la colonialidad donde viven unos frente a otros; pero la cuestión central aquí es, de qué hablamos cuando se dice "desarrollo humano".

El problema más sensible está relacionado con el modo de pensar del hombre, quien se encuentra preocupado básicamente en acumular bienes de consumo y riqueza financiera. Así, cuanto más dinero tenga un ciudadano en una de sus cuentas, y mayor cantidad de bienes y servicios consuma, mayor posibilidad de pertenencia a un nivel socioeconómico desarrollado. Cuestión que en términos de producción se expresa: cuanto más capital se acumule, en distintas escalas, más desarrollado se estará. No interesa cómo ni cuáles sean las formas de incrementar la riqueza, lo que importa es cuánto de riqueza se acumule. Esta situación también pone al descubierto acciones inmorales bajo la temible mascara que "el fin justifica los medios". El problema radica en esta "preocupación del hombre" que ha convertido nuestras sociedades en aldeas inhumanas donde la "gente" no es el fin último, sino el medio para alcanzar los intereses privados y particulares que en muchos casos genera exclusión, explotación e injusticia social.

El enfoque del desarrollo humano, dirigido desde el PNUD, tiene que ver directamente con el bienestar humano. Los aspectos por los cuales se dirige el desarrollo humano son básicamente dos. Primero: La formación de capacidades humanas, para mejor estado de salud, incremento de conocimientos y mayores destrezas. Segundo: El uso de las capacidades adquiridas, para el descanso, la producción y la participación en actividades culturales, sociales y políticas.

Ahora bien, relacionar directamente el entorno sociocultural del hombre con su bienestar personal es necesario, para saber de qué manera y cómo nos preparamos para el disfrute del bienestar, a partir de esto, se puede empezar a evaluar ¿qué buscamos en la vida?, y si aquello que buscamos nos lleva realmente a la felicidad. En todos los casos la felicidad dependerá directamente del entorno 
social, la vida comunitaria y las interrelaciones humanas nos convierten en seres humanos que se necesitan unos a otros, aun cuando lo que se necesita es tan solo un bien (material), el bienestar radica en la convivencia social.

Ramón León Donayre en su (2012) La psicología y su contribución al proceso de desarrollo social del Perú, señala la importancia de la psicología para la superación de los problemas sociales que se interpretan como problemas nacionales, y sostiene que "la rama de la psicología a la que atañe el mayor nivel de responsabilidad en el proceso de estudio, comprensión y superación de los problemas de nuestra sociedad es la psicología social" (: 455). Ahora bien, el anhelo radica en que las sociedades se involucren con una realidad menos injusta, más digna y segura, para Ramón León la importancia de los psicólogos en el Perú radica en que se acerquen a observar la sociedad, pues la vida cotidiana presenta múltiples conductas que se expresan en la mayoría de casos como machismo, homofobia, racismo, violencia, entre otros, pues estos casos son modos tan peculiares de vida que requieren un estudio y un interés científico para su interpretación.

Pero caracterizar el impacto de la felicidad en los seres humanos, a partir de la cantidad de bienes de consumo, no se aleja del todo de la realidad actual. Ya que con el afán del bienestar, se juzga a la colectividad humana con la percepción superficial de que la felicidad radica en comer y beber. Se desvirtúa el fundamento esencial de que la felicidad radica en el mismo ser humano, o mejor dicho, la felicidad radica en el alma de los seres humanos quienes lo concientizan. En la sociedad peruana actual, recurrimos a expresiones tan usuales para efectos de marketing como "Destapa felicidad", "Saborea felicidad"; sin embargo, podemos apreciar que la felicidad en el Perú, caracterizada en determinados bienes de consumo, no generan directamente la anhelada "felicidad", si por ejemplo tenemos en frente a una mujer que bajo el efecto de "saborea felicidad" comió excesivamente de aquello que le producía satisfacción, finalmente ella terminó con indigestión y con altos índices de colesterol que la llevaron a caer en una ingesta inapropiada y ella solamente sufrió y se perjudicó cambiando su estado radicalmente hacia el estado de infelicidad. De tal modo, se buscará fortalecer las emociones positivas, para acrecentar un estado de conciencia hacia la vida moral que favorezca, el sentir humano desde lo esencialmente favorable para la personalidad y la conducta humana. 


\section{REFERENCIAS BIBLIOGRÁFICAS}

Alarcón, R. (2000). Historia de la psicología en el Perú. Lima: Universidad Ricardo Palma, Editorial Universitaria.

(2002). Estudios sobre psicología latinoamericana. Lima: Universidad Ricardo Palma, Editorial Universitaria.

(2009). Psicología de la felicidad. Introducción a la psicología positiva. Lima: Universidad Ricardo Palma, Editorial Universitaria.

(2011). Psicología contemporánea. Ensayos. Lima: Universidad Ricardo Palma, Editorial Universitaria.

Aristóteles (2003). Ética a Nicómaco. Madrid: Gredos. Traducción y notas por Julio Pallí Bonet, 1985, primera edición, 6ta reimpresión.

León Donayre, R. (2010). La literatura psicológica del siglo XX. Una mirada. Lima: Universidad Ricardo Palma, Editorial Universitaria.

(2012). «La psicología y su contribución al proceso de desarrollo social del Perú». En Libro en homenaje al doctor Iván Rodríguez Chávez. Derecho y literatura. Tomo II. Lima: Universidad Ricardo Palma. Editorial Universitaria, pp. 449-478.

(2014). «Los ensayos acerca de la psicología contemporánea, de Reynaldo Alarcón». Teoría e investigación en Psicología. Revista de la Facultad de Psicología de la Universidad Ricardo Palma. Vol. 20, Mayo, pp.149-156.

Ugarriza Chávez, N. (2014). «Un nuevo libro de Reynaldo Alarcón Napurí Psicología contemporánea. Ensayos». Teoría e investigación en Psicología. Revista de la Facultad de Psicología de la Universidad Ricardo Palma. Vol. 20, Mayo, pp.157-163. 